\title{
Reflexiones Jurídicas Contemporáneas. Libro Homenaje al Doctor Pedro López Ríos
}

\author{
Autor: Teresita Rendón Huerta Barrera y \\ José Jesús Soriano Flores (coords.), \\ Universidad de Guanajuato, México, 2015
}

Por: Juan Luis HERNÁNDEZ MACÍAS ${ }^{1}$

La investigación científica-jurídica en la Universidad de Guanajuato ha pasado por diversos y diferenciados estadios desde su implementación en el otrora Departamento de Investigaciones Jurídicas. Este proyecto, hoy desfasado por una nueva estructura institucional y capital humano, fue cuna de las primeras discusiones académicas en torno a las grandes preguntas de las ciencias jurídicas. De la misma forma, los primeros arbitrajes de textos con pretensión científica fueron arbitrados por pares, sólo que entonces, no fueron ciegos. Así, el reducido claustro de profesores investigadores mantuvo álgidas discusiones todos los martes en la sala del Pleno de Investigaciones Jurídicas. Uno de sus principales impulsores fue Pedro López Ríos, quien bien asesorado por su padre académico, el Maestro Héctor FixZamudio, fundó los cimientos de una de las actividades imprescindibles en el entendimiento de la modernidad en nuestra Universidad de Guanajuato.

A décadas de lo narrado, la profesora Rendón Huerta Barrera y el profesor Soriano Flores, asisten a la concepción de un proyecto de rigor académico que fungirá como homenaje al Maestro Pedro López Ríos, como profesor, como juzgador, como persona, como científico del derecho y más importante, como universitario. El homenaje en cuestión -como no podría ser de otra forma - fue sometido a la revisión por pares dando así cuenta de un fenómeno de transformación por el que han pasado las comunidades científicas, particularmente la del derecho en nuestra Universidad. En tiempos anteriores, muchos de los honorables profesores y profesoras fueron homenajeados por la comunidad jurídica de nuestra entidad y nuestro país a través de un amplio catálogo de libros que fueron editados bajo el sello de la Universidad de Guanajuato. Entonces, fueron libros que surgieron desde la academia, la consultoría, la judicatura y la práctica jurídica en general. Empero, el hecho de que esta sea una obra cuyos artículos han sido arbitrados, da cuenta de un proceso que no tiene vuelta atrás: la revisión y puesta en escrutinio del trabajo que pretende ser publicado por pares. Valga la mención, actividad que ha impregnado todas las áreas investigativas de la actual

\footnotetext{
${ }^{1}$ Integrante del Programa Universitario de Investigaciones Jurídicas de la División de Derecho, Política y Gobierno de la Universidad de Guanajuato. Correo electrónico: jlhernandezmacias@gmail.com
} 
División de Derecho, Política y Gobierno. Ya en sus publicaciones periódicas o bien, hasta su semillero más básico, el Programa Universitario de Investigaciones Jurídicas.

El resultado de este trabajo ha sido publicado y presentado en 2015. Son veintitrés artículos los que conforman la presente obra y veintinueve autores quienes han puesto sobre el papel sus conocimientos especializados y que han quedado integrados en esta varia de distintas ramas del derecho con un par de destellos de la ciencia política y la administración pública, consolidando de esta forma la estructura divisional en la que coexistimos con otras ciencias sociales afines con las cuales, además, compartimos objetos de estudio desde distintos miradores.

En el análisis de la obra es posible percibir la vuelta de los autores sobre las grandes ramas del Derecho. Una clasificación genérica de los contenidos, nos pueden llevar a dividir el caudal de artículos aquí publicados en por los menos las siguientes categorías: 1) Derecho de la administración pública; 2) Derecho constitucional y derechos humanos; 3) Estudios de la política; 4) Derecho Penal y 5) Derecho Civil y Notarial. ${ }^{2}$

En la primera de ellas Derecho de la administración pública encontraremos las aportaciones de diversos juristas que a continuación se enumeran: Gerardo Arroyo Figueroa, quien escribe sobre la nueva Ley de Asociaciones Público-Privadas; Miguel Ángel Cervantes Flores, quien hace un recuento sobre los pilares de la justicia contenciosa administrativa en México; Carlos Eduardo Hernández Pérez, quien por su parte discute la vigencia del sistema de méritos en la administración pública de este siglo; José Ángel Méndez Rivas y Antonio Olguín Torres, a su vez, indagan en las posibles relaciones entre el derecho administrativo internacional y el derecho internacional del medio ambiente; José de Jesús Ramírez Macías, quien desde la administración pública ofrece un estudio de caso sobre intervención territorial en los municipios del noreste del estado de Guanajuato; Alejandro Armando Ramírez Zamarripa, igualmente desde el método casuístico, ofrece una propuesta de regulación de la participación ciudadana municipal a partir del caso de los consejos municipales en la ciudad de León, Guanajuato; Teresita Rendón Huerta Barrera argumenta jurídicamente en aras del aprovechamiento de residuos sólidos urbanos en materia energética; Jessica C. Romero Michel, estudia el alcance de la responsabilidad patrimonial del Estado en aquellos casos en que colisionan la integridad patrimonial y la reparación del daño; y por último en este amplio apartado, Alejandro Sánchez García, discurre sobre el derecho fundamental a la buena administración pública.

En un segundo bloque temático el lector encontrará las disquisiciones en materia de $D e$ recho constitucional y derechos humanos, cuyos participantes son: Antonio Silverio Martínez Hernández, quien estructura un contraste histórico del control constitucional difuso y concentrado y sus orígenes en México; Juan Antonio Rodríguez Corona, por su parte deconstruye para su análisis el paradigma de la defensa de la Constitución y su influencia en las cartas fundacionales; Salvador Francisco Ruíz Medrano, desde su aportación, analiza los vínculos entre propiedad intelectual a la luz de los derechos humanos; los profesores Manuel Vidaurri Aréchiga, José Jesús Soriano Flores y Fátima Rostro Hernández, por su parte, ponen sobre la mesa la discusión al respecto de los derechos políticos como derechos

\footnotetext{
${ }^{2}$ No sobra decir que estas categorías se delimitan a los fines de esta reseña, el lector no encontrará esta clasificación en la obra que aquí se comenta.
} 
humanos; por último en esta sección, he aportado un texto en el que estudio la labor de los jueces constitucionales cuando se enfrentan al juicio de ponderación de principios jurídicos.

En un tercer apartado que hemos denominado Estudios de la política encontraremos textos como el de la profesora Patricia Begné, quien escribe sobre la participación ciudadana en el nivel básico de gobierno, es decir, el municipio; Guillermo Rafael Gómez Romo de Vivar, desde el derecho electoral esboza argumentos en pos de la construcción de un modelo anticorrupción partidista; Julio César Kala, a su vez, ofrece una disertación al respecto de la cultura política como cultura de la legalidad; los profesores Enoc Morán Torres y Angélica Yedit Prado Rebolledo, estudian el problema del abstencionismo electoral en el periodo de transición democrática en México; y para cerrar este apartado, Jean Eddy Saint Paul, Elizabeth Zapata Azpiri y María Guadalupe Márquez Algara estudian la coacción física y la coerción fiscal en el marco del estado moderno, esto desde la perspectiva de la sociología y el derecho.

En el breve pero claramente identificables apartado de Derecho Penal encontramos dos aportaciones: en un primer lugar, el texto de Pablo Alfonso Cervantes quien ofrece un análisis dogmático y político-criminal sobre el feminicidio en Guanajuato y por otra parte Liliana Hernández Mendoza escribe al respecto del principio non bis in ídem y sus antecedentes.

Un último eje temático, igualmente breve, es el del Derecho Civil y Notarial. Dos artículos lo conforman, el primero de ellos es del profesor emérito José Cervantes Herrera quien analiza de fondo el tema de la licencia en la Ley del Notariado en Guanajuato; y para finalizar el profesor Salvador Soto Guerrero escribió sobre las nuevas tecnologías y sus retos probatorios para el derecho familiar.

El entramado tan rico y variado de temáticas que los investigadores especialistas en sus áreas han aportado para este merecido libro homenaje da cuenta de la necesidad y avidez de quienes se dedican - ya de tiempo completo o parcial - a la investigación desde y para el conocimiento y estudio científico de lo jurídico. La carrera prolífica y entrega de Pedro López Ríos ha sido reconocida de manera rigurosa y respetuosa por quienes, de alguna forma, habrán de seguir los pasos hacia el loable oficio del investigador, mismo que el jurista guanajuatense ahora homenajeado ha dejado como digno ejemplo a las presentes y futuras generaciones. 